Supporting Information

\title{
The Coalescence, Spreading, and Rebound of Two Water Droplets with Different Temperatures on Superhydrophobic Surface
}

Hao Xu, ${ }^{\dagger}$ Chao Chang, ${ }^{\dagger \dagger}$ Nan Yi, ${ }^{\dagger}$ Peng Tao, ${ }^{\dagger}$ Chengyi Song, ${ }^{\dagger}$ Jianbo Wu, ${ }^{\dagger}$ Tao Deng, ${ }^{*}+$ Wen Shang ${ }^{*, \dagger}$

${ }^{\dagger}$ State Key Laboratory of Metal Matrix Composites, Advanced Energy Materials and Technology Center, School of Materials Science and Engineering, Shanghai Jiao Tong University, 800 Dongchuan Road, Shanghai, 200240, P. R. China

${ }^{\ddagger}$ Institute of Marine Engineering and Thermal Science, Marine Engineering College, Dalian Maritime University, Dalian 116026, P. R. China

E-mail: dengtao@sjtu.edu.cn or shangwen@sjtu.edu.cn 
1. Optical image of the experimental setup.

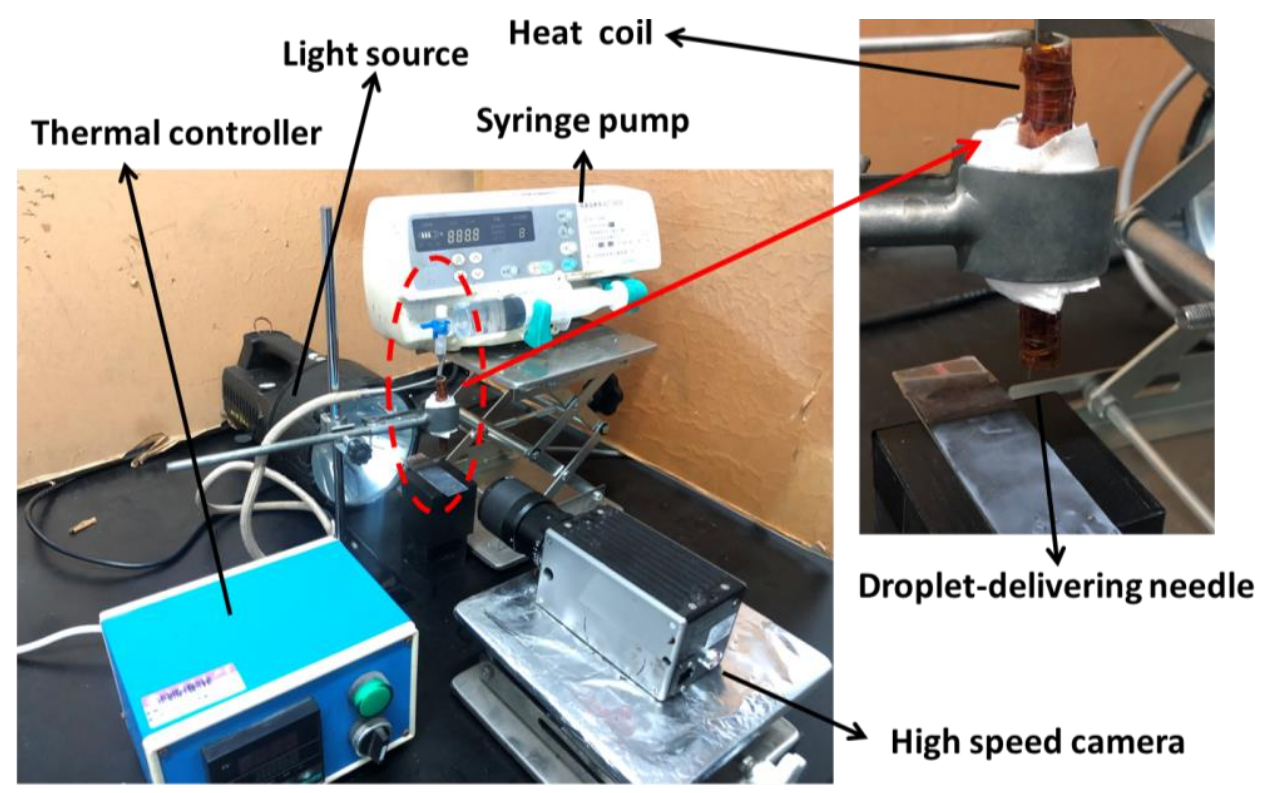

Figure S1. Optical image of the experimental setup.

2. The supplementary snapshots of coalescence process for Figure 3 of the main manuscript.

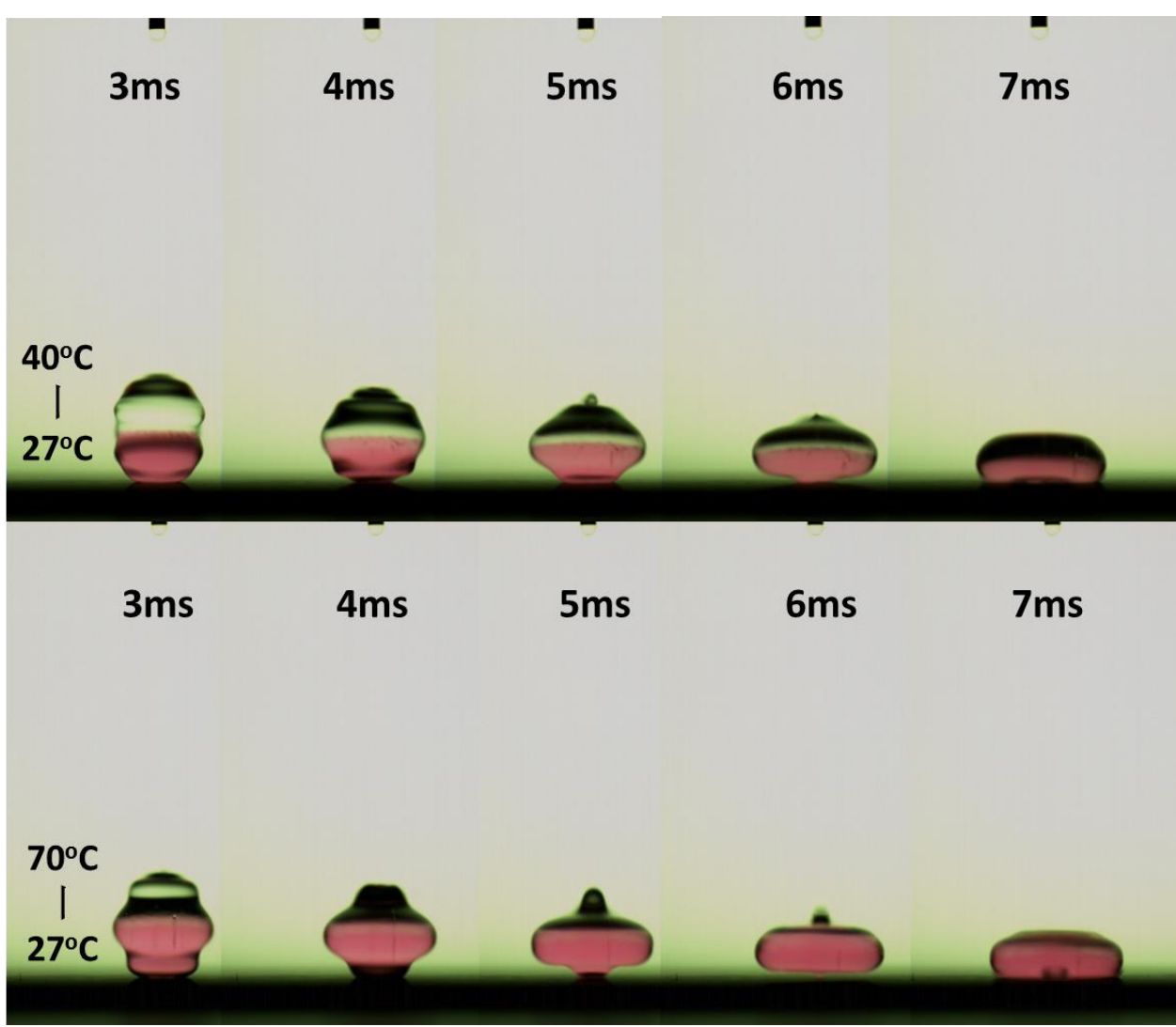

Figure S2. Snapshots of coalescence from $3 \mathrm{~ms}$ to $7 \mathrm{~ms}$ for Figure $3 \mathrm{~b}$ and $3 \mathrm{c}$. 
3. Measurement of advancing and receding contact angles of the droplets on superhydrophobic surface. The droplets were placed on the SiNW surface, which sits on a sample stage. The sample stage was gradually rotated and the images just before the droplets rolling off from the surface were used to measure the advancing and receding angles. The measured advancing angle was $\sim 162^{\circ} \pm 2^{\circ}$ and receding angle was $\sim 147^{\circ} \pm 2^{\circ}$.

4. Coalescence of droplets with different sizes and releasing height of impacting droplets.

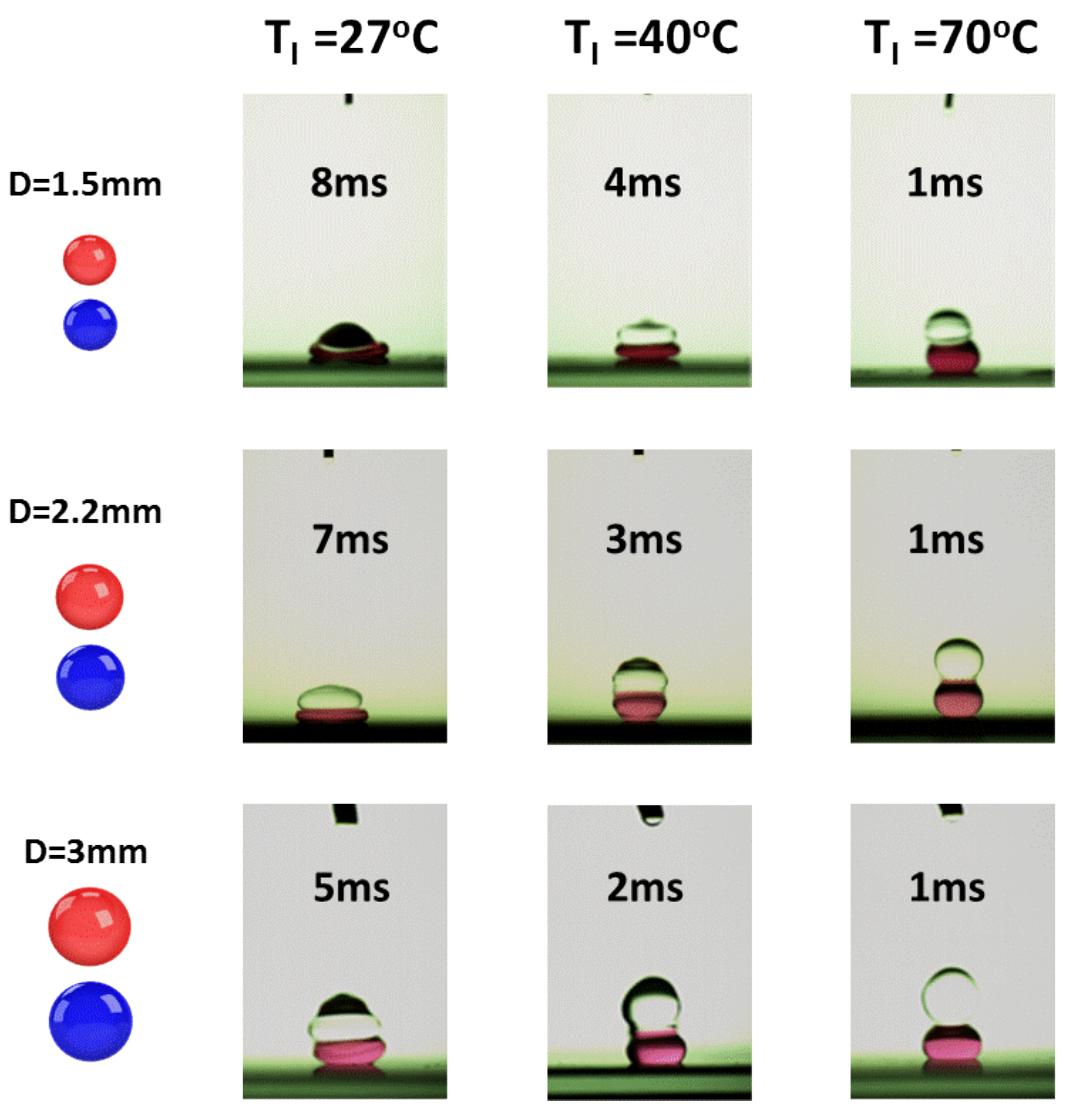

Figure S3. The starting moment of coalescence at $\mathrm{T}_{\mathrm{I}}=27^{\circ} \mathrm{C}, 40^{\circ} \mathrm{C}$, and 70 ${ }^{\circ} \mathrm{C}$, with the diameters of both the stationary and impacting droplets changing from $1.5 \mathrm{~mm}$ to $2.2 \mathrm{~mm}$, and to $3 \mathrm{~mm}$. Similar trend of accelerated coalescence with the increase of $T_{I}$ was observed for all sizes studied in this work. 


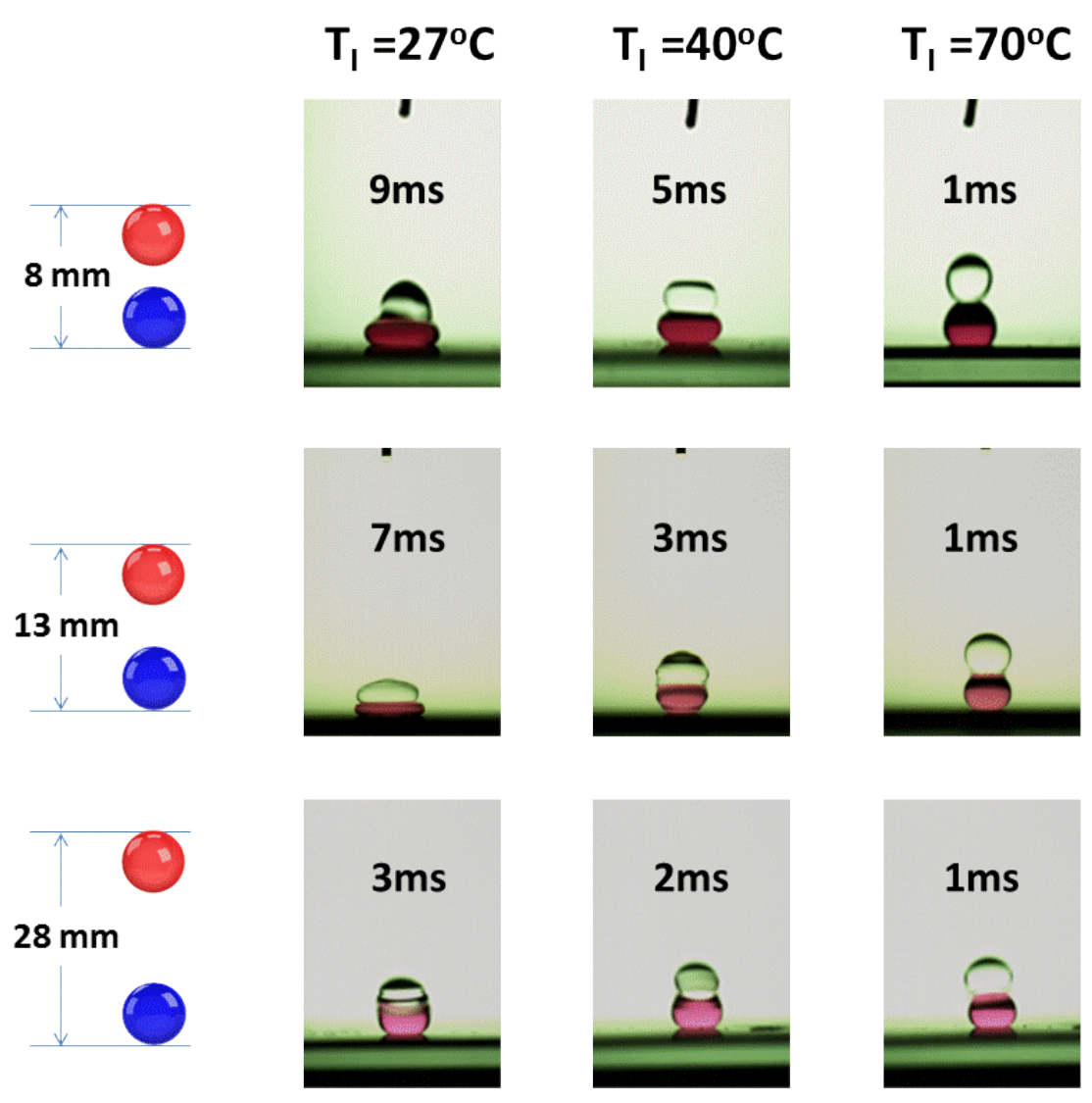

Figure S4. The starting moment of coalescence at $\mathrm{T}_{\mathrm{I}}=27^{\circ} \mathrm{C}, 40^{\circ} \mathrm{C}$, and 70 ${ }^{\circ} \mathrm{C}$, with the releasing height of the impacting droplets changing from $8 \mathrm{~mm}$ to $13 \mathrm{~mm}$, and to $28 \mathrm{~mm}$. Similar trend of accelerated coalescence with the increase of $\mathrm{T}_{\mathrm{I}}$ was observed for all releasing heights studied in this work.

\section{Heat transfer inside the merged droplet during the first impact/rebound} event.

Based on the video image analysis, the hot water (transparent) in all cases was at the top of the cold water (red color) in the merged droplets. The heat diffusion length (L) from the hot water to the cold water can be estimated using the following Equation 1:1

$$
\mathrm{L}=\left(\mathrm{tK} / \rho \mathrm{C}_{\mathrm{p}}\right)^{0.5}
$$

where $\mathrm{K}$ is the thermal conductivity of water, $\rho$ is the density of water, $\mathrm{C}_{\mathrm{p}}$ is the heat 
capacity of water, and $t$ is the time scale of the heat transfer. The contact time between the first impact and rebound is around $22 \mathrm{~ms}$, and $\mathrm{L}$ in this duration is estimated to be $\sim 57 \mu \mathrm{m}$. Such short heat diffusion length implies that there is almost no heat transfer from the hot water to the cold water during the first impact event. The temperature of the water surface in contact with the superhydrophobic surface thus remained to be the same as the suphydrophobic surface (room temperature, $\sim 27^{\circ} \mathrm{C}$ ) and there was no heat transfer from the water droplet to the underlying superhydrophobic surface.

\section{The change of the surface energy and kinetic energy of the two droplets.}

At the beginning, the total energy is the sum of the surface energy and gravitational potential energy of the impacting droplet, and the surface energy of the stationary droplet. When the merged droplets deformed on the SH surface and reached maximum spreading, most energy was converted to surface energy. During the impacting process the gravitational potential energy was converted to the kinetic energy:

$$
\mathrm{E}_{\mathrm{k}}=\mathrm{mg} \Delta \mathrm{h}
$$

in which $E_{K}$ is the kinetic energy, $m$ is the mass of the droplet, $g$ is the gravitational constant, and $\Delta \mathrm{h}$ represents the maximum height of the droplet from the surface of the substrate.

When the droplet is in the air, the surface free energy can be evaluated as:

$$
\mathrm{G}_{1}=4 \pi R^{2} \gamma
$$

in which $G_{1}$ is the surface free energy of the droplet, $R$ is the radius of the droplet, and $\gamma$ is the surface tension of the liquid.

When the two droplets are merged and spread to maximum length on the surface, most energy is converted into surface energy: ${ }^{2}$

$$
\mathrm{G}_{\mathrm{s}}=\pi R_{\max }^{2} \gamma\left(1-\cos \theta_{a}\right)
$$

in which $G_{s}$ is the surface free energy of the spreading droplet, $R_{\max }$ is the maximum spreading radius of the merged droplet, and $\theta_{a}$ is the advancing contact angle. 
Figure S5 shows the change of the kinetic energy and surface energy of the droplets at temperature $27{ }^{\circ} \mathrm{C}$ and $45^{\circ} \mathrm{C}$ during $1^{\text {st }}, 2^{\text {nd }}$, and $3^{\text {rd }}$ impact and spreading processes.

At $27{ }^{\circ} \mathrm{C}$, the energy dissipation of the first collision was large and almost all the kinetic energy was lost, while the surface energy did not change much. Then the merged droplet hardly jumped up. After the first collision, the energy transition was almost completed. Contrary to the case of $27^{\circ} \mathrm{C}$, the energy loss in the first collision at $45{ }^{\circ} \mathrm{C}$ was much smaller, and the energy transition continued during the subsequent cycles. The change of surface energy was much larger than the change of kinetic energy, which indicated that the dominant energy form during the process was the surface energy. 


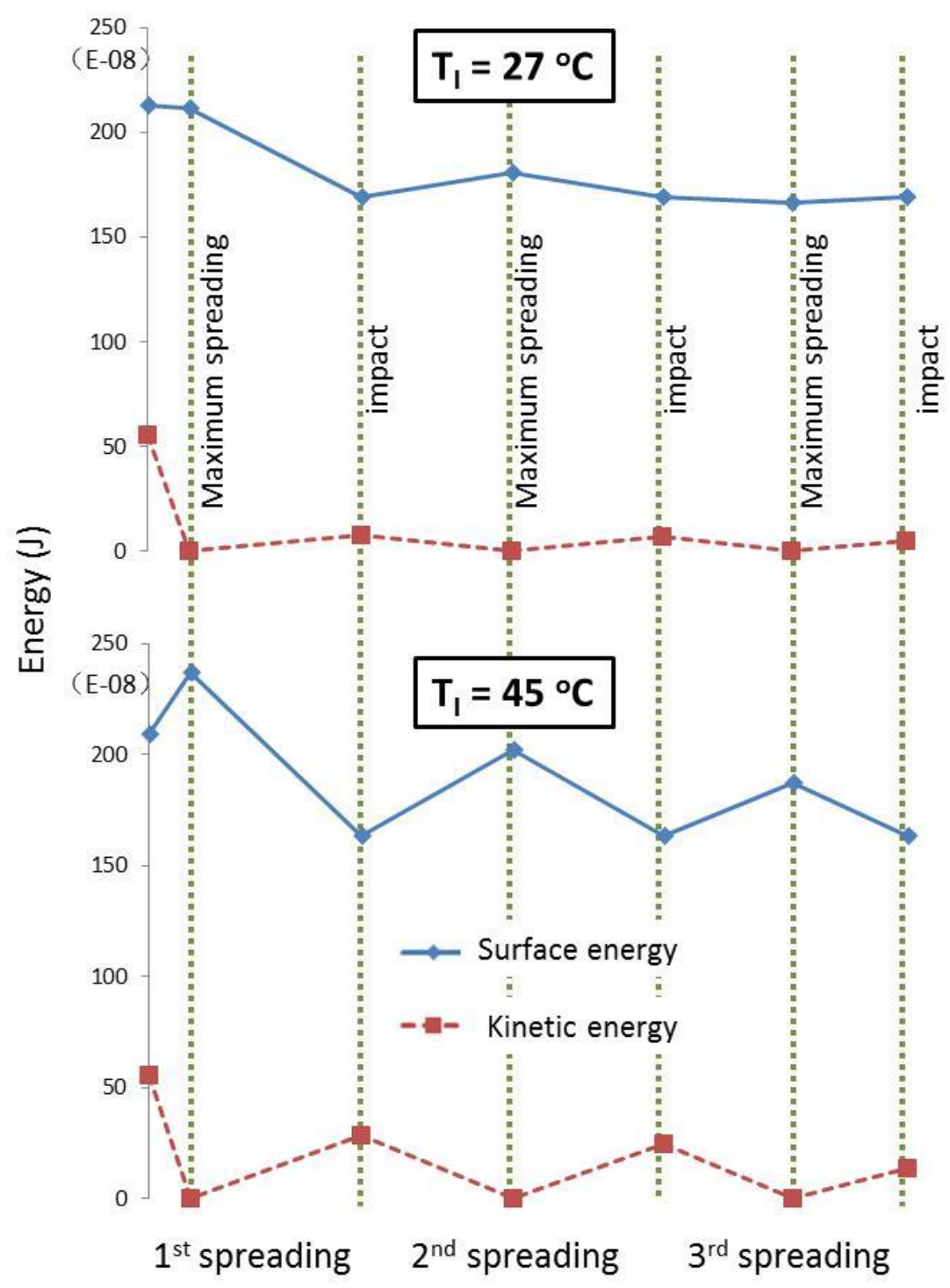

Figure S5. The change of surface energy and the kinetic energy of the merged droplets when the impacting droplet was set at $27{ }^{\circ} \mathrm{C}$ and $45^{\circ} \mathrm{C}$.

7. The change of total surface energy for the two droplets before the impact and for the merged droplets just before rebounding.

Table S1. The change of total surface energy for the two droplets system.

\begin{tabular}{ccccc}
\hline $\begin{array}{c}\text { Droplets } \\
\text { temperature }\end{array}$ & $\begin{array}{c}\text { Before impacting } \\
(\mathrm{J})\end{array}$ & $\begin{array}{c}\text { Before } \\
\text { rebounding }(\mathrm{J})\end{array}$ & $\begin{array}{c}\text { Change of } \\
\text { total surface } \\
\text { energy }(\mathrm{J})\end{array}$ & $\begin{array}{c}\text { Theoretic } \\
\text { restitution } \\
\text { coefficient }\end{array}$ \\
\hline $27-27^{\circ} \mathrm{C}$ & $2.18 \times 10^{-6}$ & $1.73 \times 10^{-6}$ & $0.45 \times 10^{-6}$ & 0.9002
\end{tabular}


$45-27^{\circ} \mathrm{C}$

$2.13 \times 10^{-6}$

$1.69 \times 10^{-6}$

$0.44 \times 10^{-6}$

0.8964

$70-27^{\circ} \mathrm{C}$

$2.07 \times 10^{-6}$

$1.65 \times 10^{-6}$

$0.42 \times 10^{-6}$

0.8887

\section{REFERENCES}

(1) Alizadeh, A.; Yamada, M.; Li, R.; Shang, W.; Otta, S.; Zhong, S.; Ge, L.; Dhinojwala, A.; Conway, K. R.; Bahadur, V.; Vinciquerra, A. Dynamics of ice nucleation on water repellent surfaces. Langmuir 2012, 28, 3180.

(2) Farhangi, M. M.; Graham, P. J.; Choudhury, N. R.; Dolatabadi, A. Induced detachment of coalescing droplets on superhydrophobic surfaces. Langmuir 2012, 28, 1290. 